\title{
AUSTENITE STABILIZATION OF Fe-Ni ALLOY
}

\author{
V.E. DANILCIIENKo \\ Metal Physics Institute, Ukrainian Academy of Science \\ Vernadsky Av. 36, Kícv 252142, Ukraine \\ AND A.V. NEDOLYA \\ Department of Physics, Zaporozhye University \\ Zhukovsky Str. 66, Zaporozliye 330600, Ukraine
}

\begin{abstract}
By X-ray powder difraction and magnetometric methods we investigated the efrect of phase lardening during $\gamma-\alpha-\gamma$ transitions. In this case austenite becomes more stable to subsequent $\gamma-\alpha-\gamma$ transitions, the dislocation density increases, the grain reduce in fragments and the hardness increases, too. In addition, the $\gamma$-solid solution in some steels is unstable during ageing. The plase hardening was found to stabilize the $\gamma$-solid solution of $\mathrm{Fe}-\mathrm{Ni}$ alloy to subsequent thermal treatment. This is consistent with an increase in carbon mobility after $\gamma-\alpha-\gamma$ transitions. That is why decarbonizations of austenite take place during increase in extent of plase hardening.
\end{abstract}

PACS numbers: 61.10.Lx, 61.50.Kis

It is known that the unit cell volumes of the fcc austenite (the so-called $\gamma$-phase) and bec martensite (the so-called $\alpha$-phase) differ about $6 \%$. This is why the $\gamma-\alpha-\gamma$ transformations ("cycling") induce internal strains referred to as phase hardening, which increase with the number of cycles. During $\gamma \leftrightarrow \alpha$ transitions specimens are strengthening significantly: its yield strengthens by more than three times (with remaining plastic properties), time resistance -1.5 times, hardness -1.6 times [1, 2]. In the case of carbon free Fe-Ni alloys austenite stabilization was observed [1]. While in the case of alloys containing carbon, both stabilization and activation of austenite wcre observed near to the $\gamma \leftrightarrow \alpha$ transitions [ [3, 4]. After a cycle of $\gamma \leftrightarrow \alpha$ transitions, the austenite grains were reduced to fragments with several orientations, and the density of dislocations was found to increase up to 1000 times in austenite lattice. In addition, in the course of the investigation, it was found that there were essential changes in thermal stability of the $\gamma$-solid solution of thermocycled $\mathrm{Fe}-\mathrm{Ni}$ alloys.

$\mathrm{Fe}-\mathrm{Ni}$ alloy $(0.58 \% \mathrm{C}, 20.2 \% \mathrm{Ni}, 2.9 \% \mathrm{Mo}, 0.18 \% \mathrm{Si}, 0.03 \% \mathrm{P}, 0.04 \% \mathrm{~S})$ having polycrystalline austenite structures at room temperature was investigated. The martensitic $\gamma-\alpha$ transformation took place during liquid nitrogen cooling. The 
reverse $\alpha-\gamma$ transition was conducted after heating of specimens in a salt bath at $620-630^{\circ} \mathrm{C}$ temperature. The characteristics of martensitic transformations were measured by the magnetic method both during cooling and after subsequent heating up to room temperature. The eflect of high temperature lieating was investigated after quenching with water at room temperature. The austenite lattice parameter was measured by $\mathrm{X}$-ray powder diftraction using $(220)_{\gamma}$ and $(311)_{\gamma}$ diffraction reflexes. The time of ageing at each temperature was 30 minutes.

After heating the steel in its initial condition, the thermal instability of the carbon $\gamma$-solid solution was observed. This caused the nonmonotonous dependence of the $a_{\gamma}$ lattice parameter (Fig. 1, curve 1). This instability is connected with

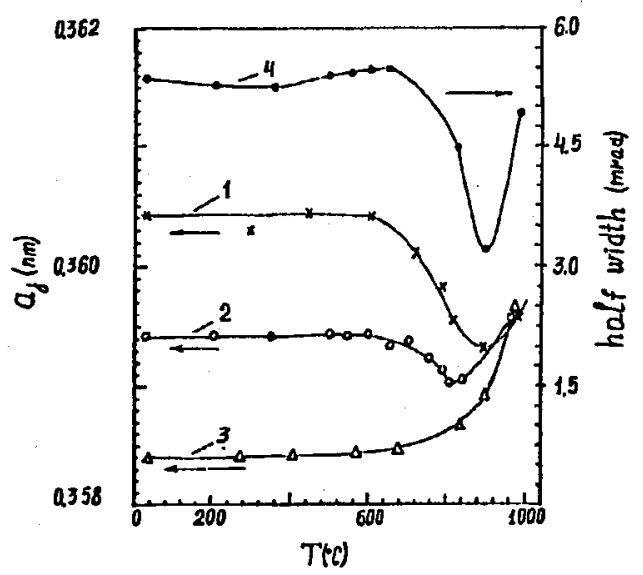

Fig. 1. Change of austenite lattice parameter of $\mathrm{Fe}-0.58 \% \mathrm{C}-20.2 \% \mathrm{Ni}-2.9 \% \mathrm{Mo}-0.18 \%$ Si-0.03\% $\mathrm{P}-0.04 \% \mathrm{~S}$ during step heating: 1 - intitial condition, $2-$ after a cycle of transitions, 3 - after 30 cycles of transitions, $1-\mathrm{X}$-ray diffraction reflex halfwidth (200) of initial steel.

partial precipitation of carbon from the solid solution lattice. After heating up to maximum temperatures of $880-900^{\circ} \mathrm{C}$, carbide precipitation with cementite type was discovered by $\mathrm{X}$-ray powder diffraction. When the ageing temperature was increased, the $\mathrm{X}$-ray diffraction reflexes arising from carbides became weaker and totally disappeared at $950^{\circ} \mathrm{C}$. After the subsequent cooling to room tcmperature the specimen regained its austenite structure.

During the cooling of stcel in its initial condition to liquid nitrogen temperature, about $65 \%$ of martensite was formed; in the case of aged steel $\left(880^{\circ} \mathrm{C}\right.$, 30 minutes) the output of martensite was $78 \%$. After heating of this $65 \%$ martensite containing steel up to the $\alpha-\gamma$ transition temperature, the carbon solubility of reserved austenite was found to be not complete. This corresponded to about $0.16 \mathrm{wt} \%$ carbon precipitation from the $\gamma$-solid solution (Fig. 1, curve 2). During ageing of steel carbide is formed. That is why the instability of the $\gamma$-solid solution could be caused by precipitation of not only carbon but also Mo. Therefore, the calculations of $\gamma$-solid solution carbon contents took into account that austenite 
lattice parameter differed insignificantly when Mo contents changed in the 1-3\% range [5]. The temperature of maximum instability of thermocycled austenite in steel was found to move to lower temperatures by $70^{\circ} \mathrm{C}$, but magnetometric measurement showed the transition in thermocycled austenite took place at the same temperature as it did in the initial steel.

An increase in the number of thermal cycles led to further depletion of $\gamma$-solid solution by carbon (Fig. 1, curve 3 ). After heating the cycled austenite at $900^{\circ} \mathrm{C}$ gradual dissolution of carbon was observed and, as a result, the lattice parameter increased. After heating to $1000^{\circ} \mathrm{C}$ the $\gamma$-solid solution composition for all specimens were equal irrespective of their previous thermal treatment.

After these processing step the interval stress of austenite was found to decrease as evidenced by a decrease in the hallwidth of the reflex $(200)_{\gamma}$ (Fig. 1 , curve 1,4$)$. For the purpose of comparison the influence of thermal cycling treatment on the austenite lattice structure of a different carbon-free $\mathrm{Fe}-\mathrm{Ni}$ alloy $(27.8 \%$ $\mathrm{Ni}, 3.1 \% \mathrm{Ti}, 1.8 \% \mathrm{Al}$ ) was investigated. The thermal instability of this alloy was different from that of carbon-containing alloys. It has been shown previously [6] that the lattice parameter changes nonmonotonously with a minimum at $660^{\circ} \mathrm{C}$. This is connected with metastable intermetallic compound precipitates, of $\mathrm{Ni}_{3}(\mathrm{Ti}, \mathrm{Al})$ $\gamma^{\prime}$-type, which are coherent with the austenitic matrix [7].

In this publication we have shown that phase hardening caused by $\gamma \leftrightarrow \alpha$ transitions intensifies the $\gamma$-solid solution instability of $\mathrm{Ni}-\mathrm{Ti}-\mathrm{\Lambda l}$ containing steel. After 5 cycles the $a_{\gamma}$ parameter decreased by $0.0005 \mathrm{~mm}$. After that austenite was stable to subsequent $\gamma \leftrightarrow \alpha$ transitions. The indicated instability of $a_{\gamma}$ was probably connected with an increasing dispersity of $\gamma^{\prime}$-particles and as a result, the coherence of their lattice with the austenite lattice.

The stability of $\mathrm{Fe}-\mathrm{Ni}-\mathrm{C}$ alloy (austenite structure) by carbon precipitation depends considerably on thermal cycling through the $\gamma \leftrightarrow \alpha$ transition. After a cycle, the $\gamma$-solid solution was depleted by carbon in the instability interval. After multiple cycles additional subgrain boundaries and high dislocation density were formed in austenite. The result was 2.5-3 times higher mobility of carbon atoms and a higher diffusion velocity [8]. The increase in the degree of phase hardening as a result of increased number of cycles led to additional decarbonization of $\boldsymbol{\gamma}$-solid solutions and eliminated the nommonotonous change of the parameter. Therefore, the decrease in the $\gamma$-solid solution lattice parameter taking place during thermal cycling should be connected not only with phase hardening of austenite but also with ageing processes in the $\alpha-\gamma$ transition interval.

\section{References}

[1] V.G. Gorbuch, Melallophysilia (USSR) 27, 5 (1970).

[2] K.A. Malyshev, V.V. Sagaradze, I.P. Sorokin, N.D. Zemsova, V.A. Teplov, A.I. Uvarov, Phase-Hardening of Fe-Ni Austenile Alloys, Nauka, Moskva 1982, p. 260.

[3] V.I. Bondar, V.V. Girghon, V.E. Danilchenko, Fiz. Met. Melalloved. (USSR) 1, 159 (1991). 
[4] V.I. Bondar, V.E. Danilchenko, A.V. Nedolya, Mater. Sci. Forum 133-136, 449 (1993).

[5] L.I. Mirkin, X-Ray Conlrol of Machine Industry Malerials, Machine Industry Books, Moskva 1979, p. 132.

[6] V.E. Danilchenko, V.A. Okhrimenko, Fiz. Met. Metalloved. (USSR) 63, 329 (1987).

[7] Yu.N. Koval, V.V. Kokorin, Fiz. Met. Melalloved. (USSR) 39, 1044 (1975).

[8] A.C. Tichonov, V.V. Belov, I.G. Leushin, Thermalcycling Treatment of Sleel, Alloys and Composile, Nauka, Moskva 1982, p. 260. 